\title{
MICROWAVE-ASSISTED EXTRACTION OF PHENOLIC COMPOUNDS FROM POLYGONUM MULTIFLORUM THUNB. ROOTS
}

\author{
Le Pham Tan Quoc ${ }^{1,2 \bowtie}$, Nguyen Van Muoi ${ }^{1}$ \\ ${ }^{1}$ Department of Food Technology, College of Agriculture and Applied Biology, Can Tho University \\ Campus II 3/2 street, Ninh Kieu district, Can Tho city, Vietnam \\ ${ }^{2}$ Institute of Biotechnology and Food Technology, Industrial University of Ho Chi Minh City \\ No. 12 Nguyen Van Bao, Ward 4, Go Vap district, Ho Chi Minh city, Vietnam
}

\begin{abstract}
Background. The aim of this study was to determine the best extraction conditions for total phenolic content (TPC) and antioxidant capacity (AC) of Polygonum multiflorum Thunb. root using microwave-assisted extraction (MAE).

Material and methods. The raw material used was Polygonum multiflorum Thunb. root powder. Five factors such as solvent type, solvent concentrations, solvent/material ratio, extraction time and microwave power were studied; TPC and AC values were determined by the Folin-Ciocalteu method and DPPH free radical scavenging activity measurement, respectively. In addition, studies involved assaying the HPLC test of extracts and SEM of samples.

Results. Optimal results pointed to acetone as the solvent, acetone concentration of $60 \%$, solvent $/$ material ratio of 40/1 (v/w), extraction time of 5 mins and microwave power of $127 \mathrm{~W}$. TPC and AC obtained were approximates $44.3 \pm 0.13 \mathrm{mg} \mathrm{GAE} / \mathrm{g}$ DW and $341.26 \pm 1.54 \mu \mathrm{mol} \mathrm{TE} / \mathrm{g} \mathrm{DW}$, respectively. The effect of microwaving on the cell destruction of Polygonum multiflorum Thunb. root was observed by scanning electron microscopy (SEM). Some phenolic compounds were determined by the HPLC method, for instance, gallic acid, catechin and resveratrol.

Conclusion. These factors significantly affected TPC and AC. We can use acetone as a solvent with microwave-assisted extraction to achieve the best result.
\end{abstract}

Key words: antioxidant capacity, microwave-assisted extraction, Polygonum multiflorum Thunb., solvent, total polyphenol, Trolox

\section{INTRODUCTION}

Exploitation of phenolic compounds in plants has been studied for decades, because they are antioxidant substances and can prevent many diseases, especially certain forms of cancer (Hung et al., 2004). Polygonum multiflorum Thunb. was among the precious plants, its root was used as medicine thousands of years ago in Asia. Polygonum multiflorum Thunb. is a member of the Polygonaceae family and is referred to as "Ha Thu
O Do" (HTOD) in Vietnam. There are two forms of HTOD: as a natural root and its processed form, which were traditional Chinese and Vietnamese medicine material. HTOD was used widely for the treatment of tonic tension (Lim et al., 2014), cancer (Way et al., 2014), anti-aging effects (Lim et al., 2008) and antioxidant activity (Wang et al., 2008a). There are a great number of bioactive compounds in HTOD, including

『lephamtanquoc@yahoo.com, phone +84906 413493 
flavonoids, quinones, stilbenes and phospholipids. So far, scientists have found many new compounds in HTOD, but their structures have not yet been identified (Qiu et al., 2013), especially phenolic compounds. They are used widely in many fields, for instance, the food industry and medicine. Some studies show that many valuable phenolic compounds exist in HTOD, such as resveratrol (Xu et al., 2009), catechin (Chen et al., 1999) and flavonoids (Li and Lin, 1993), etc.

There are many methods to extract phenolic compounds and one of them is microwave-assisted extraction (MAE). In recent years, MAE has been widely applied for extracting bioactive subtracts from plants and has become popular for phenolic compounds extraction, such as Sour Cherry Pomace (Simsek et al., 2012), Rosmarinus officinalis (Švarc-Gajic et al., 2013), Canarium album L. (He and Xia, 2011), etc. In comparison with conventional methods, MAE reduces the amount of solvents, cuts the extraction time considerably and increases the yield (Huie, 2002).

Currently, no research has presented the MAE method for the extraction of phenolic compounds from HTOD. Hence, the goal of study was to determine the extraction conditions including solvent type, solvent concentration, extraction time, and solvent/ material ratio for the extraction of total phenolic content from HTOD. In addition, the antioxidant capacity of the root extracts was analyzed.

\section{MATERIAL AND METHODS}

\section{Plant material and sample preparation}

Polygonum multiflorum Thunb. roots were harvested from Cao Bang province (Vietnam) and the cleaned roots were sliced and dried at $60^{\circ} \mathrm{C}$ until a $<12 \%$ moisture level was reached. The slices were ground into a fine powder $(<0.5 \mathrm{~mm})$ and vacuum-packed.

\section{Chemicals and reagents}

Folin-Ciocalteu and DPPH (2,2-diphenyl-1-picrylhydrazyl, purity: $\geq 90 \%)$ reagent were purchased from Merck (Germany). A trolox (6-hydroxy-2,5,7,8-tetramethylchroman-2-carboxylic acid, purity: 97\%) reagent was purchased from Sigma-Aldrich (USA) and all other chemicals and organic solvents were of analytical reagent grade.

\section{Extraction of phenolic compounds}

Root powder ( $1 \mathrm{~g}$ ) was extracted using deionized water, $60 \%$ methanol, $60 \%$ ethanol and $60 \%$ acetone as a solvent. The optimal solvent was tested as a mixture with water at different concentrations $(30,40,50,60$, 70 and $80 \%$ ), solvent/material ratios $(20 / 1,30 / 1,40 / 1$, $50 / 1$ and $60 / 1, \mathrm{v} / \mathrm{w})$, extraction times $(1,3,5,7$ and 9 minutes) and microwave powers $(74,127,195,327$ and $610 \mathrm{~W})$. The extraction process was carried out using a home-made modified microwave machine (Sanyo, Japan). The extracts obtained were filtered through Whatman No. 4 filter paper and evaporated under vacuum conditions in a water bath at $45^{\circ} \mathrm{C}$, the residue was redissolved by the same extraction solvent, the extracts were stored at $4^{\circ} \mathrm{C}$ for subsequent analysis then their TPC and AC were determined.

\section{Determination of total polyphenol content (TPC)}

The TPC in the extracts was slightly modified and determined by the Folin-Ciocalteu colorimetric method (Premakumari et al., 2010). The results were based on a standard curve obtained with gallic acid. TPC were expressed as mg of gallic acid equivalents per gram of dry weight (mg GAE/g DW).

\section{Determination of antioxidant capacity (AC)}

The AC in the extracts was determined by DPPH assay; this method was slightly modified and described by Soto et al. (2014). Trolox was used as the standard. $\mathrm{AC}$ was expressed in TEAC (Trolox equivalent antioxidant capacity) determined as $\mu \mathrm{mol}$ of Trolox per gram of dry weight ( $\mu \mathrm{mol} \mathrm{TE} / \mathrm{g} \mathrm{DW})$.

\section{Scanning electron micrographs (SEM)}

A scanning electron microscope system (Jeol JSM$7401 \mathrm{~F}$, USA) was used to examine morphological changes in dried powder from the Polygonum multiflorum Thunb. root before and after extraction.

\section{Determination of phenolic compounds by HPLC}

HPLC analysis of phenolic compounds in Polygonum multiflorum Thunb. roots extracts was carried out on a Agilent 1100 Series HPLC system equipped a diodearray UV-vis detector. The analysis was performed on a reversed-phase column (Kromasil C18, 150 $\times 2.1 \mathrm{~mm}$, $3.5 \mu \mathrm{m})$; the sample was injected into the injection port (loop $20 \mu \mathrm{L}$ ). The UV detector was set at a wavelength 
of $270 \mathrm{~nm}$ and $308 \mathrm{~nm}$ for gallic acid, catechin and resveratrol, respectively. The flow rate was always $0.2 \mathrm{~mL} / \mathrm{min}$ at $30^{\circ} \mathrm{C}$. Standard phenolic compound solutions were prepared in the solvent used in the extractions. The analysis was performed using a gradient program with a two-solvent system (A: $0.1 \%$ Triethylamine/ $\mathrm{HCl} ; \mathrm{B}$ : methanol). The gradient program was as follows: $0 \mathrm{~min}, 10 \% \mathrm{~B} ; 5 \mathrm{~min}, 10 \% \mathrm{~B} ; 15 \mathrm{~min}, 30 \%$ B; 20 min, 30\% B; 21 min, $100 \%$ B; 21.5 min, 10\% B; $30 \min , 10 \% \mathrm{~B}$.

\section{Data analysis}

Experimental results were analyzed by the one-way analysis of variance (ANOVA) method and significant differences among the means from triplicate analyses at $(p<0.05)$ were determined by Fisher's least significant difference (LSD) procedure using Statgraphics software (Centurion XV). The values obtained were expressed in the form of a mean \pm standard deviation (SD).

\section{RESULTS AND DISCUSSION}

\section{Effect of solvent type on extraction of phenolic compounds}

There are many different types of solvents used in the extraction of polyphenols from plant such as methanol, ethanol, hexane, acetone, chloroform, diethyl ether and water (Dezashibi et al., 2013). In this study, the four usual solvents used to determine the most suitable one for the extraction of phenolic compounds included distilled water, $60 \%$ acetone, $60 \%$ methanol and $60 \%$ ethanol (Proestos and Komaitis, 2008). The experimental process is performed with microwave-assisted extraction at a microwave power of $195 \mathrm{~W}$, solvent/material ratio of $40 / 1$ and extraction time of 5 minutes. The results are showed in Table 1 below.

Basically, almost polyphenols in plants are the polar compounds. Therefore, they were extracted with many aqueous organic solvents (Benmeziane et al., 2014). The results showed that aqueous acetone was the optimal solvent and more useful for extracting polyphenols from HTOD extracts because TPC and $\mathrm{AC}$ have maximum values. The polarity of solvents is arranged in descending order: water $>$ methanol $>$ ethanol $>$ acetone (Tan et al., 2013) and combinations of organic solvents with water can improve the extraction of phenolic compounds (Bucić-Kojić et al., 2011). In this study, phenolic compounds dissolved well in aqueous acetone and had the highest antioxidant activity. This solvent has also been proved to be more efficient than other organic solvents for the extraction of phenolic compounds from different materials, for instance, neem leaves (Hismath et al., 2011), grape mac (Vatai et al., 2009) and soybean (Lien et al., 2015). Therefore, aqueous acetone was chosen as the extraction solvent for the next experiments.

\section{Effect of solvent/material ratio on extraction of phenolic compounds}

The most important parameter affecting the MAE process is the solvent/material ratio. The proper ratio choice will improve TPC and AC. The optimal results of TPC and AC obtain $45.84 \pm 0.77 \mathrm{mg} \mathrm{GAE} / \mathrm{g} \mathrm{DW}$ and $345.37 \pm 13.34 \mu \mathrm{mol} \mathrm{TE} / \mathrm{g} \mathrm{DW}$ at a solvent/material ratio of 40/1, respectively (Table 2) and this ratio is chosen for subsequent experiments. An increase in the solvent/material ratio can lead to an increase in the diffusion rate (Cacace and Mazza, 2003), resulting in an increase in TPC, AC and the extraction process is stopped when the diffusion process obtains the

Table 1. TPC and AC of extracts at various solvents

\begin{tabular}{lcccr}
\hline & \multicolumn{4}{c}{ Solvents } \\
\cline { 2 - 5 } & water & $60 \%$ Ace & $60 \% \mathrm{MeOH}$ & $60 \% \mathrm{EtOH}$ \\
\hline TPC, $\mathrm{mg} \mathrm{GAE} / \mathrm{g}$ DW & $39.43^{\mathrm{a}} \pm 2.14$ & $44.25^{\mathrm{b}} \pm 1.03$ & $39.82^{\mathrm{a}} \pm 0.58$ & $42.63^{\mathrm{b}} \pm 0.43$ \\
TEAC, $\mu \mathrm{mol} \mathrm{TE} / \mathrm{g}$ DW & $108.24^{\mathrm{a}} \pm 1.50$ & $347.68^{\mathrm{b}} \pm 21.03$ & $268.15^{\mathrm{c}} \pm 11.08$ & $236.50^{\mathrm{d}} \pm 7.84$ \\
\hline
\end{tabular}

Various lowercase letters in the same row denote significant difference $(p<5 \%)$ between extraction solvents. 
Quoc, L. P. T. , Van Muoi, N. (2016). Microwave-assisted extraction of phenolic compounds from Polygonum multiflorum Thunb. roots. Acta Sci. Pol. Technol. Aliment., 15(2), 181-189. DOI: 10.17306/J.AFS.2016.2.18

Table 2. TPC and AC of extracts at various solvent/material ratios

\begin{tabular}{lrrrrr}
\hline & \multicolumn{5}{c}{ Solvent/material ratios } \\
\cline { 2 - 6 } & \multicolumn{1}{c}{$20 / 1$} & \multicolumn{1}{c}{$30 / 1$} & $40 / 1$ & \multicolumn{1}{c}{$50 / 1$} & $60 / 1$ \\
\hline TPC, mg GAE/g DW & $15.45^{\mathrm{a}} \pm 1.09$ & $36.68^{\mathrm{b}} \pm 1.43$ & $45.84^{\mathrm{c}} \pm 0.77$ & $41.98^{\mathrm{d}} \pm 0.78$ & $38.93^{\mathrm{e}} \pm 1.52$ \\
TEAC, $\mu \mathrm{mol}$ TE/g DW & $206.9^{\mathrm{a}} \pm 2.48$ & $344.78^{\mathrm{b}} \pm 3.79$ & $345.37^{\mathrm{b}} \pm 13.34$ & $335.81^{\mathrm{b}} \pm 7.07$ & $336.83^{\mathrm{b}} \pm 4.09$ \\
\hline
\end{tabular}

Various lowercase letters in the same row denote significant difference $(p<5 \%)$ between solvent/material ratios.

equilibrium. However, $\mathrm{AC}$ was not significantly different $(p<0.05)$ between solvent/material ratios from $30 / 1$ to $60 / 1$.

This extraction process is consistent with mass transfer principles; the driving force during mass transfer is the concentration gradient between liquid and solid (Al-Farsi and Chang, 2008). However, the high solvent/material ratio means more energy and time is required to optimize the extraction process. The results have low values because of non-uniform distribution and exposure to microwaves (Eskilsson et al., 1999).

Furthermore, a low solvent/material ratio could create difficulties in the filtration process, as phenolic compounds are absorbed by dry material (Kossah et al., 2010) and not completely extracted phenolic compounds from the materials.

\section{Effect of acetone concentrations on the extraction of phenolic compounds}

The effects of acetone concentrations on TPC and AC are presented in Table 3 . The maximum result is an acetone concentration of $60 \%$, while TPC and AC are $43.73 \pm 2.30 \mathrm{mg}$ GAE$/ \mathrm{g}$ DW and $341.65 \pm 11.72 \mu \mathrm{mol}$ $\mathrm{TE} / \mathrm{g}$ DW, respectively. Then they decrease with a further increase in the acetone concentration of the extraction process.
In this study, the properties of the solvent can be changed when combining different solvents (acetone and water), which allow solvent selectivity for different phenolic compounds (Brachet et al., 2002) and different antioxidant capacities. Therefore, the extract has the highest TPC and AC values at a suitable polarity of solvent. The small amounts of water in the solvent allow the diffusion of water into the plant cells, leading to better heating and facilitating the transport of bioactive substances into the extracting solvent at higher mass transfer rates (Chemat and Cravotto, 2013). Conversely, large amounts of water can solve many different organic compounds as sugar and protein, which affects TPC and AC (Jafari et al., 2011). Water is also quite important in the MAE process, as it has a good polarity (high dielectric constants) and can absorb more microwave energy, hence the extraction efficiency is better (Kaufmann et al., 2001). Accordingly, the organic solvents combined with water create a moderately polar solvent, which ensures the optimal extraction of phenolic compounds.

From the results obtained, it appears that anacetone concentration of $60 \%$ is the optimal condition for subsequent experiments.

Table 3. TPC and AC of extracts at various acetone concentrations

\begin{tabular}{lrrrrrr}
\hline & \multicolumn{6}{c}{ Acetone concentrations, $\%$} \\
\cline { 2 - 7 } & \multicolumn{1}{c}{30} & \multicolumn{1}{c}{40} & \multicolumn{1}{c}{50} & \multicolumn{1}{c}{60} & \multicolumn{1}{c}{70} & \multicolumn{1}{c}{80} \\
\hline TPC, mg GAE/g DW & $32.70^{\mathrm{a}} \pm 0.57$ & $37.24^{\mathrm{b}} \pm 1.21$ & $42.80^{\mathrm{c}} \pm 1.60$ & $43.73^{\mathrm{c}} \pm 2.30$ & $39.23^{\mathrm{b}} \pm 1.12$ & $39.09^{\mathrm{b}} \pm 1.54$ \\
TEAC, $\mu$ mol TE/g DW & $205.88^{\mathrm{a}} \pm 6.28$ & $269.28^{\mathrm{b}} \pm 5.68$ & $307.60^{\mathrm{cd}} \pm 1.62$ & $341.65^{\mathrm{e}} \pm 11.72$ & $318.51^{\mathrm{d}} \pm 3.15$ & $306.01^{\mathrm{c}} \pm 4.64$
\end{tabular}

Various lowercase letters in the same row denote significant difference $(p<5 \%)$ between acetone concentrations. 
Quoc, L. P. T. , Van Muoi, N. (2016). Microwave-assisted extraction of phenolic compounds from Polygonum multiflorum Thunb. roots. Acta Sci. Pol. Technol. Aliment., 15(2), 181-189. DOI: 10.17306/J.AFS.2016.2.18

Table 4. TPC and AC of extracts at various microwave powers

\begin{tabular}{lrrrrr}
\hline & \multicolumn{5}{c}{ Microwave powers, W } \\
\cline { 2 - 6 } & \multicolumn{1}{c}{74} & 127 & 195 & \multicolumn{1}{c}{327} & 610 \\
\hline TPC, mg GAE/g DW & $39.93^{\mathrm{a}} \pm 0.82$ & $43.77^{\mathrm{b}} \pm 0.51$ & $42.68^{\mathrm{c}} \pm 0.33$ & $33.26^{\mathrm{d}} \pm 0.43$ & $31.59^{\mathrm{e}} \pm 0.70$ \\
TEAC, $\mu \mathrm{mol}$ TE/g DW & $317.00^{\mathrm{a}} \pm 3.38$ & $348.73^{\mathrm{b}} \pm 15.66$ & $335.42^{\mathrm{ab}} \pm 13.23$ & $247.22^{\mathrm{c}} \pm 1.88$ & $177.64^{\mathrm{d}} \pm 9.44$ \\
\hline
\end{tabular}

Various lowercase letters in the same row denote significant difference $(p<5 \%)$ between microwave powers.

\section{Effect of microwave power on the extraction of phenolic compounds}

Table 4 shows that the optimal TPC and AC of extracts at a microwave power of $127 \mathrm{~W}$ were approximately $42.68 \pm 1.03 \mathrm{mg} \mathrm{GAE} / \mathrm{g}$ DW and $348.73 \pm 15.66 \mu \mathrm{mol}$ TE/g DW, respectively. Microwave power has a significant effect on TPC and AC $(p<0.05)$.

Microwave power affects strongly the temperature; increasing microwave power can stimulate an increase in the temperature of the solvent and raise the extraction yield until it becomes insignificant or decreases (Chemat et al., 2005; Xiao et al., 2008). At high temperatures, the viscosity and surface tension of the solvent declines, it solubilizes solutes and improves the extraction yield (Li et al., 2010; Mandal et al., 2007); however, in this study, the extraction efficiency reaches the optimal value with an increase in microwave power and then starts declining with a further increase in microwave power. Many thermally sensitive compounds are degraded at high temperatures and lose their antioxidant activity entirely. This result is in agreement with studies by Mandal et al. (2007) and Afoakwah et al. (2012). The lowest TPC and AC were $31.59 \pm 0.70 \mathrm{mg} \mathrm{GAE} / \mathrm{g} \mathrm{DW}$ and $177.64 \pm 9.44$ $\mu \mathrm{mol} \mathrm{TE} / \mathrm{g} \mathrm{DW}$ at $610 \mathrm{~W}$, these values are lower than a microwave power of $127 \mathrm{~W}$ approximately $25 \%$ and
$50 \%$, respectively. Thus, microwave power at $127 \mathrm{~W}$ is the optimal condition for subsequent studies.

\section{Effect of extraction time on extraction of phenolic compounds}

Extraction time is an important factor that influences the MAE process. The effect of extraction time on TPC and the AC of extracts has a significant difference $(p<0.05)$ and these results are shown in Table 5. At an extraction time of 5 minutes, TPC and AC registers the maximum values as $44.30 \pm 0.13 \mathrm{mg} \mathrm{GAE} / \mathrm{g} \mathrm{DW}$ and $341.26 \pm 1.54 \mu \mathrm{mol} \mathrm{TE} / \mathrm{g} \mathrm{DW}$, respectively.

Compared to conventional methods, MAE has a short extraction time (few minutes), avoiding oxidation or thermal degradation at high temperatures and long extraction time (Al-Harahshed and Kingman, 2004; Chan et al., 2011). This is very important for thermolabile compounds, especially polyphenols. At an extraction time of 9 minutes, TPC and AC registered the lowest value of $38.88 \pm 0.55 \mathrm{mg} \mathrm{GAE} / \mathrm{g}$ DW and $133.63 \pm 8.28 \mu \mathrm{mol}$ TE/g DW. These results are nearly $12 \%$ and $60 \%$ lower than at an extraction time of 5 minutes, respectively. A longer extraction time tends to improve the extraction yield. However, extraction efficiency is insignificant with longer time (Wang et al., 2008b). A solvent can influence the TPC

Table 5. TPC and AC of extracts at various extraction times

\begin{tabular}{lrrrrr}
\hline & \multicolumn{5}{c}{ Extraction times, min } \\
\cline { 2 - 6 } & \multicolumn{1}{c}{1} & \multicolumn{1}{c}{3} & \multicolumn{1}{c}{5} & \multicolumn{1}{c}{7} & 9 \\
\hline TPC, mg GAE/g DW & $37.42^{\mathrm{a}} \pm 0.33$ & $41.63^{\mathrm{b}} \pm 0.57$ & $44.30^{\mathrm{c}} \pm 0.13$ & $39.39^{\mathrm{d}} \pm 1.45$ & $38.88^{\mathrm{d}} \pm 0.55$ \\
TEAC, $\mu \mathrm{mol}$ TE/g DW & $302.88^{\mathrm{a}} \pm 8.62$ & $322.69^{\mathrm{b}} \pm 11.14$ & $341.26^{\mathrm{c}} \pm 1.54$ & $202.39^{\mathrm{d}} \pm 4.45$ & $133.63^{\mathrm{e}} \pm 8.28$ \\
\hline
\end{tabular}

Various lowercase letters in the same row denote significant difference $(p<5 \%)$ between extraction times. 
A

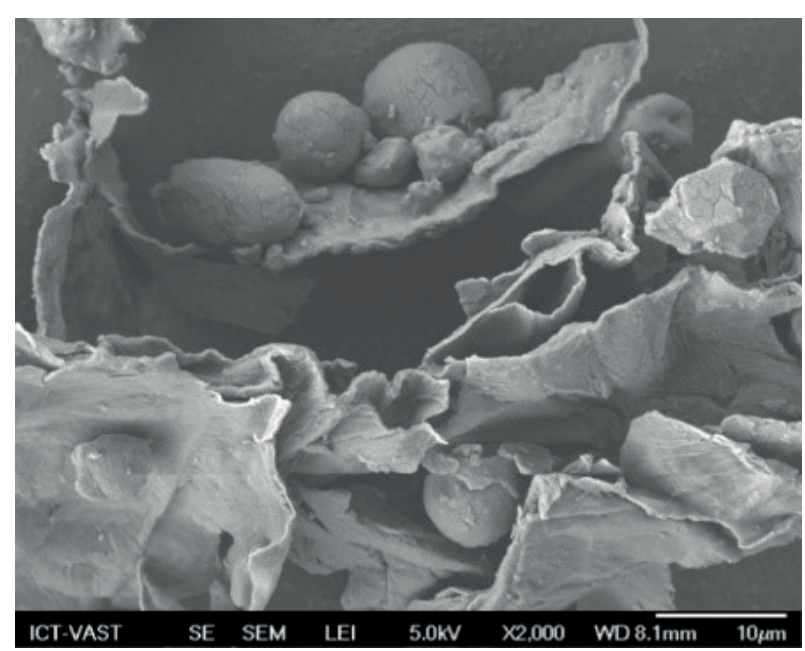

$\mathrm{B}$

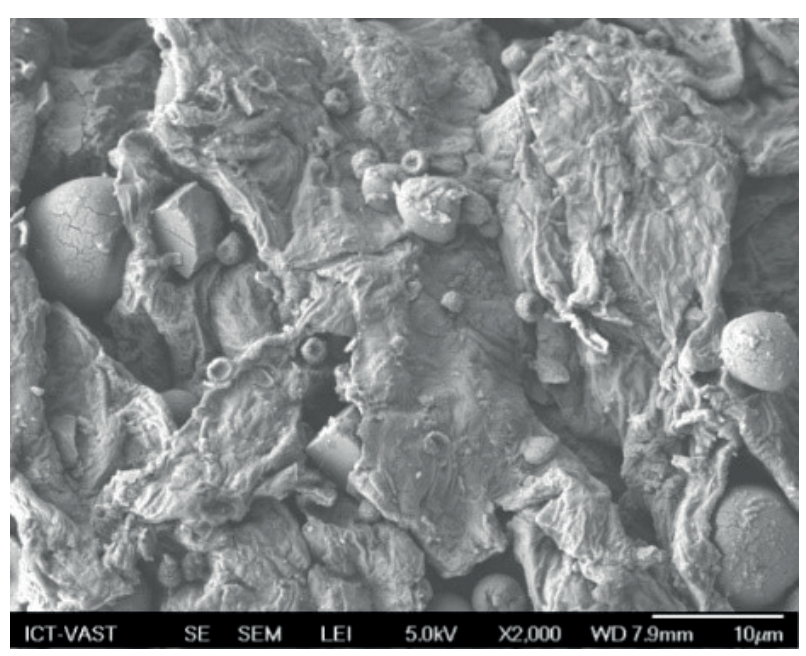

Fig. 1. Structure of material before (A) and after (B) treatment by MAE

and $\mathrm{AC}$ of the extract because the dielectric properties of the organic solvent also influence irradiation time, and it may heat up rapidly on longer exposure (Mandal et al., 2007). Hence, the extraction temperature increases significantly and destroys many bioactive compounds. Consequently, TPC and AC decrease rapidly.

\section{Effect of microwave assisted extraction on structure of material}

The dried powders of HTOD were examined by scanning electron microscopy. Based on Figure 1A, samples consist of the amount of starch and many pieces of plant cells. The starch has an oval or egg shape, is $8-20 \mu \mathrm{m}$ in diameter and the surface of the cell is smooth with few wrinkles. After treatment by MAE, the structure of the materials was changed completely, almost of the starch was gelatinized at a high temperature and some pieces of the cell wall were damaged and stuck together, with many wrinkles appearing on the surface of the cell wall (Fig. 1B). During the MAE process, the temperature and the internal pressure increased rapidly. The cell ruptured and the biochemical compounds within the cell diffused into solvents (Jyothi et al., 2010) and it is also one of the causes of the wrinkling on the surface of cells.

\section{Identification of some phenolic compounds in the extract}

Using the extracts from the optimal conditions phenolic compounds were identified by the HPLC method. The phenolic compounds detected were gallic acid $(0.78 \mathrm{mg} / \mathrm{g})$, catechin $(5.58 \mathrm{mg} / \mathrm{g})$ and resveratrol $(0.12 \mathrm{mg} / \mathrm{g}$; Fig. 3A, 3B). These compounds are similar to the research conducted by Quoc and Muoi (2015). Their study shows that the content of gallic acid, catechin and resveratrol in the HTOD extract were $0.26,1.57$ and $0.017 \mathrm{mg} / \mathrm{g}$, respectively. In addition, the results of Chang et al. (2016) show that these compounds also existed in the HTOD extract. The content of gallic acid, catechin and resveratrol were 0.146 , 0.035 and $0.192 \mathrm{mg} / \mathrm{g}$, respectively. They are fluctuant because of the differences in the environment, such as climate, soil, harvesting season, gene, storage condition and because the different extraction methods also affect the chemical components of the extracts.

\section{CONCLUSION}

The results show that acetone was the best solvent for extraction of phenolic compounds from Polygonum multiflorum Thunb. roots. The optimal conditions for maximum TPC and AC consist of an acetone 
A

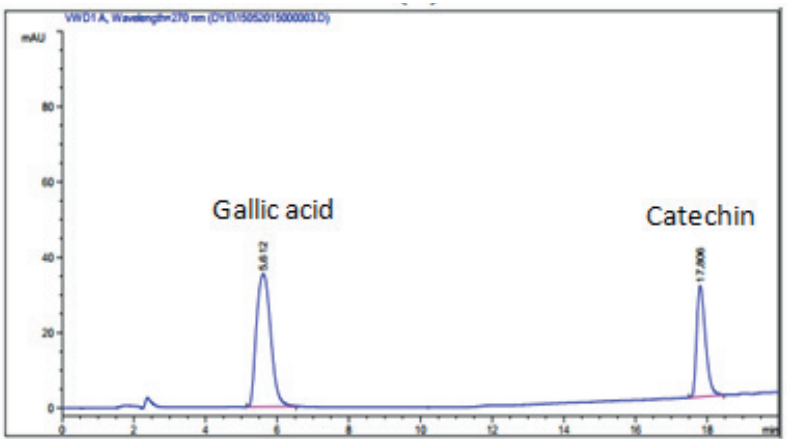

$\mathrm{B}$

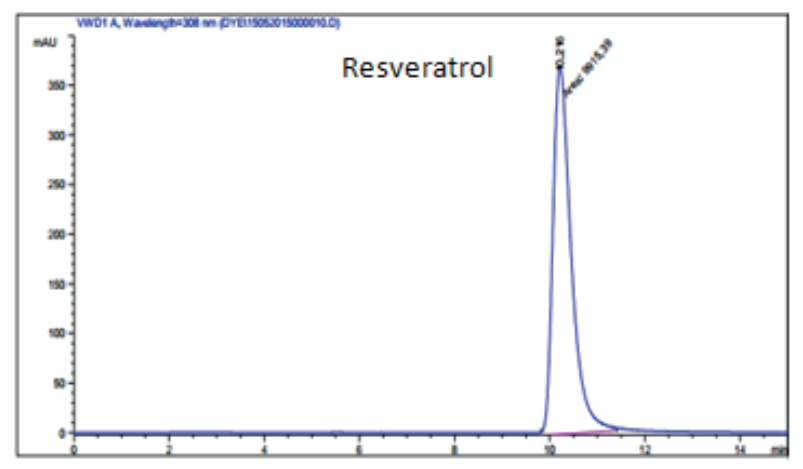

Fig. 2. HPLC chromatograms of standard sample acquired at $270 \mathrm{~nm}$ (A) and $308 \mathrm{~nm}$ (B)

A

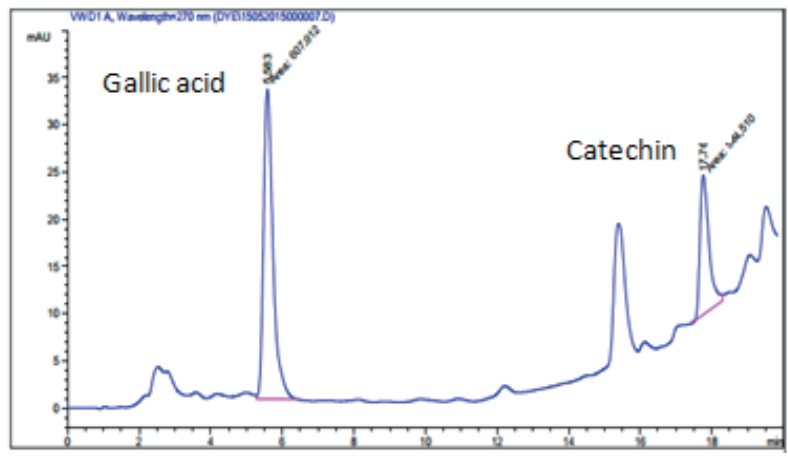

$\mathrm{B}$

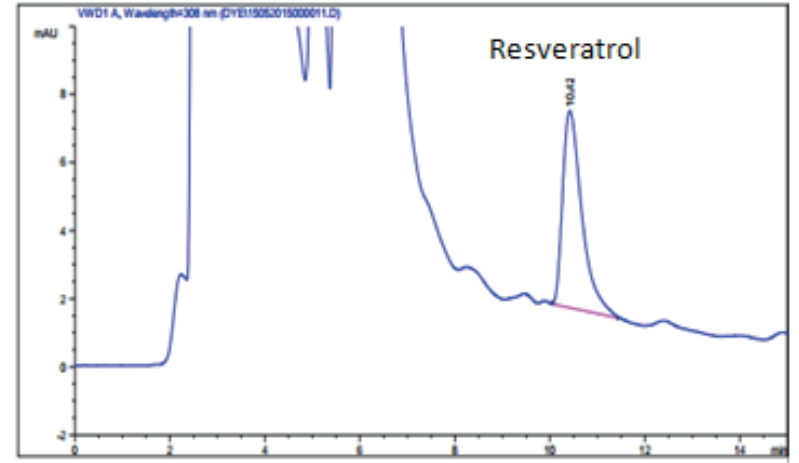

Fig. 3. HPLC chromatograms of a sample of Polygonum multiflorum Thunb. root extracts acquired at $270 \mathrm{~nm}$ (A) and 308 $\mathrm{nm}(\mathrm{B})$

concentration of $60 \%$, a solvent/material ratio of $40 / 1$ $(\mathrm{v} / \mathrm{w})$, an extraction time of 5 minutes and a microwave power of $127 \mathrm{~W}$. TPC and AC achieved approximates of $44.3 \pm 0.13 \mathrm{mg} \mathrm{GAE} / \mathrm{g} \mathrm{DW}$ and $341.26 \pm 1.54$ $\mu \mathrm{mol} \mathrm{TE} / \mathrm{g}$ DW, respectively. Cells were destroyed by MAE, wrinkles appeared on the surface and the extract had some phenolic compounds, such as gallic acid, catechin and resveratrol.

\section{ACKNOWLEDGMENTS}

This research was performed at the Institute of Biotechnology and Food Technology, Industrial University of Ho Chi Minh City (Vietnam). I would like to acknowledge my coworkers, who helped us a lot in the laboratory, including Le Phuoc Hoang, Le Tan Phong and Ta Thi Hoa.

\section{REFERENCES}

Afoakwah, A. N., Owusu, J., Adomako, C., Teye, E. (2012). Microwave assisted extraction (MAE) of antioxidant constituents in plant materials. Glob. J. Bio-sci. Biotechnol., 1(2), 132-140.

Al-Farsi, M. A., Lee, C. Y. (2008). Optimization of phenolics and dietary fiber extraction from date seeds. Food Chem., 108, 977-985.

Al-Harahshed, M., Kingman, S. W. (2004). Microwaveassisted leaching: A review. Hydrometallurgy, 73, 189-203. 
Benmeziane, F., Djamai, R., Cadot, Y., Seridi, R. (2014). Optimization of extraction parameters of phenolic compounds from Algerian fresh table grapes (Vitis Vinifera). Int. Food Res. J., 21(3), 1061-1065.

Brachet, A., Christen, P., Veuthey, J. L. (2002). Focused microwave-assisted extraction of cocaine and benzoylecgonine from coca leaves. Phytochem. Anal., 13, $162-169$.

Bucić-Kojić, A., Planinić, M., Tomas, S., Jokić, S., Mujić, I., Bilić, M., Velić, D. (2011). Effect of extraction conditions on the extractability of phenolic compounds from lyophilised fig fruits (Ficus carica L.). Pol. J. Food Nutr. Sci., 61(3), 195-199.

Cacace, J. E., Mazza, G. (2003). Mass transfer process during extraction of phenolic compounds from milled berries. J. Food Eng., 59, 379-389.

Chan, C. H., Yusoff, R., Ngoh, G. C., Kung, F. W. L. (2011). Microwave-assisted extractions of active ingredients from plants. J. Chromatogr. A, 1218, 6213-6225.

Chang, Y. X., Ge, A. H., Jiang, Y., Azietaku, J. T., Li, J., Gao, X. M. (2016). A bioactivity-based method for screening, identification of lipase inhibitors, and clarifying the effects of processing time on lipase inhibitory activity of Polygonum multiflorum. Evid.-Based Compl. Altern. Med., 2016. ID 5965067, 1-10.

Chemat, F., Cravotto, G. (2013). Microwave-assisted extraction for bioactive compounds - Theory and practice. New York, USA: Springer Press.

Chemat, S., Ait-Amar, H., Lagha, A., Esveld, D. C. (2005). Microwave-assisted extraction kinetics of terpenes from caraway seeds. Chem. Eng. Process., 44, 1320-1326.

Chen, Y., Wang, M., Rosen, R. T., Ho, C. T. (1999). 2,2-Diphenyl-1-picrylhydrazyl radical-scavenging active components from Polygonum multiflorum Thunb. J. Agric. Food Chem., 47, 2226-2228.

Dezashibi, Z., Samarin, A. M., Hematyar, N., Khodaparast, M. H. (2013). Phenolics in Henna: extraction and stability. Eur. J. Exp. Biol., 3(1), 38-41.

Eskilsson, C. S., Björklund, E., Mathiasson, L., Karlsson, L., Torstensson, A. (1999). Microwave assisted extraction of felodipine tablets. J. Chromatogr. A, 840(1), $59-70$.

He, Z., Xia, W. (2011). Microwave-assisted extraction of phenolics from Canarium album L. and identification of the main phenolic compound. Nat. Prod. Res., 25(2), 85-92.

Hismath, I., Wan Aida, W. M., Ho, C. W. (2011). Optimization of extraction conditions for phenolic compounds from neem (Azadirachta indica) leaves. Int. Food Res. J., 18(3), 931-939.
Hung, H. C., Joshipura, K. J., Jiang, R., Hu, F. B., Hunter, D., Smith-Warner, S. A., Colditz, G. A., Rosner, B., Spiegelman, D., Willett, W. C. (2004). Fruit and vegetable intake and risk of major chronic disease. J. Natl. Cancer Inst., 96, 1577-1584.

Huie, C. W. (2002). A review of modern sample preparation techniques for the extraction and analysis of medicinal plants. Anal. Bioanal. Chem., 373, 23-30.

Jafari, S. M., Rafiee, Z., Alami, M., Khomeiri, M. (2011). Microwave-assisted extraction of phenolic compounds from olive leaves. A comparison with maceration. J. Anim. Plant Sci., 21(4), 738-745.

Jyothi, D., Khanam, S., Sultana, R. (2010). Optimization of microwave assisted extraction of withanolides from roots of ashwagandha and its comparison with conventional extraction method. Int. J. Pharm Sci., 2(4), 46-50.

Kaufmann, B., Christen, P., Veuthey, J. L. (2001). Parameters affecting microwave - assisted extraction of withanolides. Phytochem. Anal., 12, 327-331.

Kossah, R., Nsabimana, C., Zhang, H., Chen, W. (2010). Optimization of extraction of polyphenols from Syrian sumac (Rhus coriaria L.) and Chinese sumac (Rhus typhina L.) fruits. Res. J. Phytochem., 4, 146-153.

Li, J. B., Lin, M. (1993). Study on the chemical constituents of Polygonum multiflorum Thunb. Chinese Trad. Herb Drugs, 3, 115-118.

Li, J., Zu, Y. G., Fu, Y. J., Yang, Y. C., Li, S. M., Li, Z. N., Wink, M. (2010). Optimization of microwave assisted extraction of triterpene saponins from defatted residue of yellow horn (Xanthoceras sorbifolia Bunge) kernel and evaluation of its antioxidant activity. Innov. Food Sci. Emerg. Technol., 11, 637-664.

Lien, D. T. P., Tram, P. T. B., Toan, H. T. (2015). Effects of extraction process on phenolic content and antioxidant activity of soybean. J. Food Nutr. Sci., 3(1-2), 33-38.

Lim, K. M., Kwon, J. H., Kim, K., Noh, J. Y., Kang, S., Park, J. M., ..., Chung, J. H. (2014). Emodin inhibits tonic tension through suppressing PKC-mediated inhibition of myosin phosphatase in isolated rat thoracic aorta. $\mathrm{Br}$. J. Pharmacol., 171(18), 4300-4310.

Lin, H. Q., Ho, M. T., Lau, L. S., Wong, K. K., Shaw, P. C., Wan, D. C. (2008). Anti-acetylcholinesterase activities of traditional Chinese medicine for treating Alzheimer's disease. Chem. Biol. Interact., 175(1-3), 352-354.

Mandal, V., Mohan, Y., Hemalath, S. (2007). Microwave assisted extraction - an innovative and promising extraction tool for medicinal plant research. Phcog. Rev., 1(1), $7-18$.

Premakumari, K. B., Siddiqua, A., Sultana, R., Vithya, S. (2010). Antioxidant activity and estimation of total 
Quoc, L. P. T. , Van Muoi, N. (2016). Microwave-assisted extraction of phenolic compounds from Polygonum multiflorum Thunb. roots. Acta Sci. Pol. Technol. Aliment., 15(2), 181-189. DOI: 10.17306/J.AFS.2016.2.18

phenolic content of Muntingia Calabura by colorimetry. Int. J. ChemTech. Res., 2(1), 205-208.

Proestos, C., Komaitis, M. (2008). Application of microwave-assisted extraction to the fast extraction of plant phenolic compounds. LWT - Food Sci. Technol., 12(4), $652-659$

Qiu, X. H., Zhang, J., Huang, Z. H., Zhu, D. Y., Xu, W. (2013). Profiling of phenolic constituents in Polygonum multiflorum Thunb. by combination of ultra-high-pressure liquid chromatography with linear ion trap-Orbitrap mass spectrometry. J. Chromatogr. A, 1292, 121-131.

Quoc, L. P. T., Muoi, N. V. (2015). Alpha-amylase-assisted extraction of polyphenolic compounds from Polygonum multiflorum Thunb. root. J. Sci. Technol., 53(4B), 31-37.

Simsek, M., Sumnu, G., Sahin, S. (2012). Microwave assisted extraction of phenolic compounds from sour cherry pomace. Sep. Sci. Technol., 47, 1248-1254.

Soto, C., Caballero, E., Pérez, E., Zúñiga, M. E. (2014). Effect of extraction conditions on total phenolic content and antioxidant capacity of pretreated wild Peumus boldus leaves from Chile. Food Bioprod. Process., 92(3), $328-333$.

Švarc-Gajic, J., Stojanovic, Z., Carretero, A. S., Román, D. A., Borrás, I., Vasiljevic, I. (2013). Development of a microwave-assisted extraction for the analysis of phenolic compounds from Rosmarinus officinalis. J. Food Eng., 119, 525-532.

Tan, M. C., Tan, C. P., Ho, C. W. (2013). Effects of extraction solvent system, time and temperature on total phenolic content of henna (Lawsonia inermis) stems. Int. Food Res. J., 20(6), 3117-3123.

Vatai, T., Škerget, M., Knez, Z. (2009). Extraction of phenolic compounds from elder berry and different grape marc varieties using organic solvents and/or supercritical carbon dioxide. J. Food Eng., 90, 246-254.

Wang, X. M., Zhao, L. B., Han, T. Z., Chen, S. F., Wang, J. L. (2008a). Protective effects of 2,3,5,4'-tetrahydroxystilbene-2-O-beta-D-glucoside, an active component of Polygonum multiflorum Thunb., on experimental colitis in mice. Eur. J. Pharmacol., 578, 339-348.

Wang, Y., You, J., Yu, Y., Qu, C., Zhang, H., Ding, L. (2008b). Analysis of ginsenosides in Panax ginseng in high pressure microwave-assisted extraction. Food Chem., 110(1), 161-167.

Way, T. D., Huang, J. T., Chou, C. H., Huang, C. H., Yang, M. H., Ho, C. T. (2014). Emodin represses TWIST1-induced epithelial-mesenchymal transitions in head and neck squamous cell carcinoma cells by inhibiting the $\beta$-catenin and Akt pathways. Eur. J. Cancer, 50, 366-378.

Xiao, W., Han, L., Shi, B. (2008). Microwave-assisted extraction of flavonoids from Radix astragali. Sep. Purif. Technol., 62(3), 614-618.

Xu, Y. L., Dong, Q., Hu, F. Z. (2009). Simultaneous quantitative determination of eight active components in $\mathrm{Po}$ lygonum multiflorum Thunb. by RP-HPLC. J. Chinese Pharm. Sci., 18, 358-361. 